\section{Kidney \\ Blood Pressure Research}

\title{
Calcitriol Supplementation Improves Endothelium-Dependent Vasodilation in Rat Hypertensive Renal Injury
}

\author{
Tsuneo Takenaka $^{a} \quad$ Tsutomu Inoue $^{b} \quad$ Yoichi Ohno $^{b} \quad$ Takashi Miyazaki $^{b}$

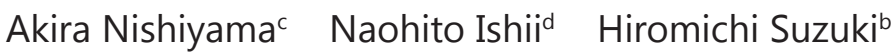

anternational University of Health and Welfare, Department of Medicine, Minato, Tokyo; bSaitama Medical University, Department of Nephrology and Community Health Science Center, Iruma Saitama; 'Kagawa University, Department of Pharmacology, Takamatsu Kagawa; ${ }^{d}$ Kitasato University, Department of Clinical Chemistry, Sagamihara Kanagawa, Japan

\section{Key Words}

Endothelium-dependent vasodilation - Insulin-like growth factor - Klotho Superoxide dismutase $•$ Transient receptor potential channels

\begin{abstract}
Background/Aims: Vitamin D increases renal expression of klotho in normotensive rats. Klotho reduces oxidative stress. Methods: In this study, we aimed to determine if vitamin D would suppress oxidative stress using 4 groups of hypertensive rats: uninephrectomized, stroke-prone, spontaneously hypertensive rats fed a high-salt (6\%) diet (controls; C); those treated with irbesartan (I); those treated with calcitriol $(\mathrm{V})$; and those treated with both irbesartan and calcitriol (I+V). Results: Systolic blood pressure was higher in the $C$ group than in the I and I+V groups. Albuminuria was attenuated in groups I, V, and I+V. Renal angiotensin II (AngII) concentration was lower in groups I and I+V than in group $C$, and plasma AngII levels of groups I and $V$ were higher and lower than those in group $C$, respectively. Compared with group $C$, renal klotho expression, 8-epi-prostaglandin F2 $\alpha$ excretion, and acetylcholineinduced decrease in blood pressure improved in the $\mathrm{V}$ and $\mathrm{I}+\mathrm{V}$ groups. Conclusions: The data indicate that irbesartan effectively decreases blood pressure and renal AngII levels, and improves albuminuria. Our findings indicate that vitamin D enhances klotho expression, suppressing oxidative stress and albuminuria without substantial changes in renal AngII levels. These results suggest that the amelioration of endothelium function by vitamin $D$ involves free klotho.
\end{abstract}




\section{Kidney Blood Pressure Research}

Takenaka/Inoue/Ohno/Miyazaki/Nishiyama/Ishii/Suzuki: Klotho and Endothelium

\section{Introduction}

The renin-angiotensin system (RAS) plays an important role in the pathogenesis of hypertension and chronic kidney disease (CKD) [1,2]. Atherosclerotic cardiovascular complications are very common among patients with CKDs, and suppression of the RAS retards the progression of renal dysfunction in various CKDs [1]. Recent findings indicate that vitamin D diminishes renin expression [3]. Thus, vitamin D may exert renoprotective effects through the inhibition of the RAS. Consistent with this, recent investigations [4, 5] demonstrated that a vitamin $D$ analogue and angiotensin receptor blocker (ARB) synergistically blocked the development of nephropathy in a model of type 2 diabetes. They reported that the ARB elevated renal angiotensin II (AngII) levels, which were lowered by the vitamin D analogue. Fried et al. [6] reported that double blockade of the RAS is not protective in CKD patients with diabetes. However, dual blockade of the RAS could be beneficial for the treatment of patients with non-diabetic CKDs. Recent investigations report that vitamin D deficiency not only causes rickets but also causes immunodeficiency, muscle atrophy, cognitive dysfunction, and high-renin hypertension [7], suggesting that vitamin D exerts extraskeletal effects apart from RAS inhibition.

Klotho is an anti-aging protein that is expressed in the kidney and parathyroid glands as a type- 1 transmembrane protein, which forms the receptor specific for fibroblast growth factor (FGF)-23 in conjunction with the canonical FGF receptor [8, 9]. Membrane klotho can be cleaved enzymatically, and the extracellular domain is released into the interstitial space as a free form of klotho. Overexpression of klotho inhibits the progression of renal dysfunction in nephritic animals and AngII-induced renal damage [10,11]. Administration of soluble klotho protein into klotho gene knockout mice increased creatinine clearance [12]. Vitamin D has a binding site upstream of the klotho gene to facilitate its expression, which causes an increase in both serum and renal klotho levels [13]. Therefore, klotho may account for some extraskeletal effects of vitamin D. However, the effects of vitamin D supplementation on renal dysfunction and klotho expression when the RAS is inhibited have not been fully assessed in the hypertensive renal injury setting. In normotensive rats, the serum 1,25-dihydroxyvitamin $\mathrm{D}(1,25$-VD) level was found to be approximately $200 \mathrm{pg} / \mathrm{mL}$ [13]. A preliminary study indicated a reduction in the 1,25-VD level in the hypertensive model used for this study. This study was performed to examine whether the progression of renal dysfunction is delayed by ARBs and vitamin D supplements in rats with hypertensive kidney injury. The effects of the ARB and vitamin D on klotho expression and endothelial function were also assessed.

\section{Materials and Methods}

\section{Animal preparation}

Six-week-old, male, stroke-prone, spontaneously hypertensive rats (SHR-sp) were purchased (Charles River Labs, Yokohama, Japan). The animals were allowed free access to tap water and rat chow. All experimental protocols were approved by ethical committee of Saitama Medical University for animal research (Permit Number: 657). This study was carried out in strict accordance with the recommendations in the Guide for the Care and Use of Laboratory Animals of the National Institutes of Health. All efforts were made to minimize suffering. Left uninephrectomy was performed in the rats anesthetized with pentobarbital sodium (50 mg/kg intraperitoneally) to induce nephrosclerosis in SHR-sp early in their lives [14]. For acclimation, each rat was housed separately in a metabolic cage for 1 week in a temperaturecontrolled room with a 12-h light-dark cycle and fed the standard diet [13]. At the age of 8 weeks, the rats were fed a high-salt diet (6\%; Nihon CLEA, Tokyo, Japan) and divided into 4 groups: SHR-sp treated with a vehicle as the control (C); those treated with irbesartan (I); those treated with calcitriol (V); and those treated with both irbesartan and calcitriol (I+V). Calcitriol (30 ng/kg/day) and irbesartan (100 mg/kg/ day) were administered via an osmotic pump that was implanted subcutaneously (Alzet, Cupertino, CA USA) and by daily subcutaneous injections, respectively. Irbesartan was dissolved in $1.5 \%$ arginine as a 


\section{Kidney \\ Blood Pressure Research}

Kidney Blood Press Res 2014;39:17-27

\begin{tabular}{l|l}
\hline DOI: 10.1159/000355773 & (C) 2014 S. Karger AG, Basel
\end{tabular}

Publisned oninne: April 30, 2014

www.karger.com/kbr

Takenaka/Inoue/Ohno/Miyazaki/Nishiyama/Ishii/Suzuki: Klotho and Endothelium

vehicle. Preliminary studies suggested that the doses of irbesartan and calcitriol used in the present study would lower blood pressure considerably and reverse the decrements of calcitriol levels without causing hypercalcemia or hyperphosphatemia in this model. A previous study reported that a high dose of alfacalcidol induced klotho expression and hypercalcemia in a hypertensive model [15]. In our study, a lower dose of calcitriol was used to circumvent the confounding effects of hypercalcemia and/or hyperphosphatemia on vascular function. Indeed, phosphate toxicity may shorten the survival of animals [16]. Six weeks after the initiation of the study, the animals were anesthetized, and the carotid and femoral arteries were cannulated using polyethylene tubing (PE50) filled with heparinized saline. Acetylcholine $(0.3 \mu \mathrm{g})$ was injected through the carotid artery directly into the aorta, and changes in the blood pressure were measured via the femoral artery. After blood pressure recovery, increasing doses of acetylcholine were administered $1 \mu \mathrm{g}$ and $3 \mu \mathrm{g}$ ). The animals were then euthanized using overdoses of anesthesia to harvest the right kidney for histopathology [17].

In additional experiments, plasma and renal AngII concentrations, plasma renin activity, and serum and renal klotho levels were measured separately in the 4 groups of rats ( $C, I, V$, and I+V; $n=6$ in each group) as described previously $[13,18-20]$. Dietary and surgical manipulations were performed as mentioned above. Urine collection and systolic blood pressure (SBP) measurements by tail cuff methods were performed every 2 weeks. Urine was collected to measure the creatinine, albumin, and 8-epi-prostaglandin F2 $\alpha$ levels. The femoral artery of the anesthetized rats was cannulated. No acetylcholine experiments were performed in this series. The right kidney was removed, and blood samples were drawn from the femoral artery and collected in chilled tubes with or without EDTA. The aorta was also removed for the reverse transcriptionpolymerase chain reaction assay. The removed right kidneys were cut in half (one for AngII concentration determination and the other for klotho expression determination) and quickly frozen with liquid nitrogen. Blood samples were centrifuged at $4^{\circ} \mathrm{C}$ for $10 \mathrm{~min}$. Plasma, serum, and tissues were kept deep-frozen until the assays were performed. Serum creatinine, calcium, phosphate, and 1,25-VD levels were also measured for this group.

\section{Histopathological analysis}

Coronal slices of the kidney were embedded in paraffin, cut into $3-\mu \mathrm{m}$ thick sections, and stained with periodic acid-Schiff reagent. All the observed sections contained hundreds of glomeruli and blood vessels, which were evaluated by two trained pathologists blinded to the classification, with a light microscope as previously described [17]. Glomerular sclerosis was graded between 0 and 3 based on the percentage surface area of involvement in each glomerulus: grade 1 represented an involvement of $<30 \%$ of a sectioned glomerular area, whereas grade 3 indicated that $>60 \%$ of the sectioned area was affected. A final overall score was calculated after individual glomeruli were graded. All the observed sections of blood vessels were graded between 0 and 3 for arteriolosclerosis, and then the final overall score of vascular alterations was calculated with the same method used for assessing glomerular alterations. The mean of the scores was calculated.

Reverse transcription-polymerase chain reaction

As described previously [21], total RNA from the aorta was extracted using a commercial kit (Isogen; Wako Pure Chemical Inc., Osaka, Japan) according to the manufacturer's instructions. Approximately $50 \mathrm{mg}$ of the aorta was homogenized in $1 \mathrm{~mL}$ of Isogen reagent in a microcentrifuge tube. Then, 200 $\mu \mathrm{L}$ of chloroform was added and the samples were vortexed for $30 \mathrm{~s}$. After centrifugation, the aqueous phase was transferred to a new microcentrifuge tube containing $0.7 \mathrm{vol}$ of isopropanol, and the RNA was recovered by centrifugation at $15,000 \mathrm{rpm}$ for $15 \mathrm{~min}$ at $4^{\circ} \mathrm{C}$. The pellet was washed in $70 \%$ cold ethanol, centrifuged, dried in a vacuum centrifugal evaporator (Tomy MV-100; Tomy Digital Biology Co., Ltd., Tokyo, Japan) for $10 \mathrm{~min}$, and dissolved in $50 \mu \mathrm{L}$ of diethyl pyrocarbonate-treated water. The concentration of dissolved RNA was estimated based on the optical absorbance at $260 \mathrm{~nm}$. One microgram of total RNA was subjected to first strand cDNA synthesis in a 20- $\mu \mathrm{L}$ reaction mixture using a commercial kit (iScript cDNA Synthesis kit; Bio-Rad Laboratories Inc., Tokyo, Japan). In a total volume of $50 \mu \mathrm{L}, 2 \mu \mathrm{L}$ of the synthesized cDNA was mixed with real-time PCR reagent (iQ SYBR Green Supermix; Bio-Rad) and specific primers for superoxide dismutase 2 (SOD; forward: 5'-CAC GAC CCA CTG CAA GGA A-3', reverse 5'-GCG TGC TCC CAC ACA TCA-3'), endothelial nitric oxide synthase (eNOS; forward: $5^{\prime}$-GCC AGG AGG GAC TGC AGT AC-3', reverse: 5'-GCG GGG AAG TGA TGT CCA GG-3'), or glyceraldehyde phosphate 


\section{Kidney Blood Pressure Research}

dehydrogenase (GAPDH; forward: 5'-AAT GCA TCC TGC ACC ACC AA-3', reverse: 5'-GTA GCC ATA TTC ATT GTC ATA-3'). The PCR was carried out in a thermal cycler (iCycler iQ System; Bio-Rad) for 40 cycles at $94^{\circ} \mathrm{C}(30 \mathrm{~s}), 60^{\circ} \mathrm{C}(30 \mathrm{~s})$, and $72^{\circ} \mathrm{C}(60 \mathrm{~s})$. Relative quantification of the SOD and eNOS mRNA was performed using the comparative threshold (CT) method. The 2- $\Delta \Delta \mathrm{CT}$ method provides a relative quantification ratio according to a calibrator that allows statistical comparisons of gene expression among samples. The CT values for the reference (GAPDH) and target genes in each sample set were determined according to the 2- $\Delta \Delta C T$ method, and changes in mRNA expression levels were calculated after normalization against GAPDH expression.

\section{Western blot}

Renal cortical klotho expression was assessed with monoclonal antibody reaction to klotho, KM2076 [13]. Each kidney sample (50 mg) was homogenized in Tris-HCl buffer ( $\mathrm{pH} \mathrm{7.5),} 150 \mathrm{mM} \mathrm{NaCl,} 0.1 \%$ Triton X-100, and $1.0 \mathrm{mM}$ phenylmethylsulfonyl fluoride in an ice bath using a Polytron homogenizer. The homogenates were centrifuged and the supernatants were used for electrophoresis. Protein content was measured using bovine serum albumin (BSA) as the standard, and treated with 2-mercaptoethanol at $95^{\circ} \mathrm{C}$ for $10 \mathrm{~min}$. Thirty micrograms of total protein was mixed with the sample buffer, boiled for 10 min and loaded, and then separated on a 7.5\% polyacrylamide gel. Separated proteins were transferred to a polyvinylidene fluoride membrane (Millipore Co., MA, USA) using a semi-dry blot transfer system (BioRad, CA, USA). The transferred polyvinylidene fluoride membranes were blocked with 5\% BSA/TBS-T solution (50 mM Tris- $\mathrm{HCl}$, pH 8.0; $150 \mathrm{mM} \mathrm{NaCl;} 0.1 \%$ Tween 20) for $3 \mathrm{~h}$ at room temperature. The blocked membrane was incubated with a primary anti-klotho antibody (1:1000 diluted in BSA/TBS-T) overnight at $4^{\circ} \mathrm{C}$. After incubation, the membranes were washed thrice with TBS solution and incubated with an antirabbit IgG peroxidase-conjugated secondary antibody (Binding Site, 1:2000 diluted) for $1 \mathrm{~h}$. An enhanced chemiluminescence (GE Healthcare Co., England) detection system was used to detect the target protein. The expression levels were analyzed using the densitometry system (ATTO AE-6920-MF, Tokyo, Japan). $\beta$-actin was used as a housekeeping protein.

\section{Immunohistochemistry}

The chimera protein of klotho (extracellular domain) and IgG (Fc) was used to detect klotho binding (Enzo Life Science, Farmingdale, NY USA). The chimera protein was diluted (1:400) in 1\% BSA using PBS as the blocking buffer and then applied to the sections for $8 \mathrm{~h}$. As detailed previously [22], the binding was detected using FITC-conjugated anti-IgG (1:40, Dako) to differentiate chimera binding to circulating and that binding to locally expressed klotho. Kidney slices were used to detect potential binding, as free klotho might bind to the tubular epithelium.

Data were expressed as mean \pm SEM. Statistical analysis was performed using analysis of variance followed by the Dunnett test. A value of $\mathrm{p}<0.05$ was considered statistically significant.

\section{Results}

In vivo data: SBP progressively increased in the $\mathrm{C}$ and $\mathrm{V}$ groups (Figure $1 \mathrm{~A}$ ). However, blood pressure was considerably lower in the I and I+V groups compared with that in the $\mathrm{C}$ group. At 2 weeks of salt loading, the SBP of group C (180 $\pm 10 \mathrm{mmHg})$ was higher than that of groups I (142 $\pm 8 \mathrm{mmHg}, p<0.01)$ and $\mathrm{I}+\mathrm{V}(140 \pm 7 \mathrm{mmHg}, p<0.01)$. At 4 and 6 weeks, these trends for SBP were maintained. As shown in Figure 1B, at 4 weeks, the increase in urinary albumin excretion (UAE) was abrogated in groups I (162 $\pm 36 \mathrm{mg} / \mathrm{g} \mathrm{Cr}$ ) and I+V $(168 \pm 38 \mathrm{mg} / \mathrm{g} \mathrm{Cr})$ compared with that in group C $(260 \pm 56 \mathrm{mg} / \mathrm{g} \mathrm{Cr}, p<0.05)$. The elevation of UAE was also suppressed in group V at 6 weeks compared with that in group C (209 \pm 46 vs. $351 \pm 75 \mathrm{mg} / \mathrm{g} \mathrm{Cr}, p<0.05)$. Glomerular sclerosis in group $\mathrm{C}$ was more advanced than $\mathrm{I}, \mathrm{V}$ and $\mathrm{I}+\mathrm{V}$ groups (Figure $1 \mathrm{C}$ ). Arteriolosclerosis was attenuated in groups I and I+V compared with that in the $\mathrm{C}$ group (Figure 1D).

Body weight or kidney weight did not differ among the 4 groups at 6 weeks. (Figure $1 \mathrm{E}$ and $1 \mathrm{~F}$ ) As shown in Figure 1G, creatinine clearance as an index of the glomerular filtration rate was preserved only in the $\mathrm{I}+\mathrm{V}$ group at 6 weeks $(1.1 \pm 0.1 \mathrm{~mL} / \mathrm{min} / \mathrm{g}$ kidney weight, 


\section{Kidney Blood Pressure Research}

Fig. 1. Temporal changes in blood pressure (A) and albumin excretion (B). Ocontrol (C), $\Delta$ irbesartan (I), •viamin $\mathrm{D}(\mathrm{V})$, uirbesartan with vitamin $\mathrm{D}(\mathrm{I}+\mathrm{V})$, albumin excretion was assessed with urinary albumin/creatinine ratio (Alb/Cr). * indicates significant difference from C (6 animals for each group). Histological examination of harvested kidney. Glomerulosclerosis (C) and arteriolosclerosis (D) were compared among 4 groups. * depicts $\mathrm{p}<0.05$ vs. C (6 animals for each group). While compensatory renal hypertrophy was observed, body (E) and kidney weights (F) were similar among 4 groups (6 animals for each group). Creatinine clearance (Ccr) was preserved in $\mathrm{I}+\mathrm{V}$ group (G) (6 animals for each group). 1,25-dihydroxy-vitamin D (1,25VD) was elevated in $\mathrm{V}$ and $\mathrm{I}+\mathrm{V}$ groups at 6 week $(H)$ (6 animals for each group).
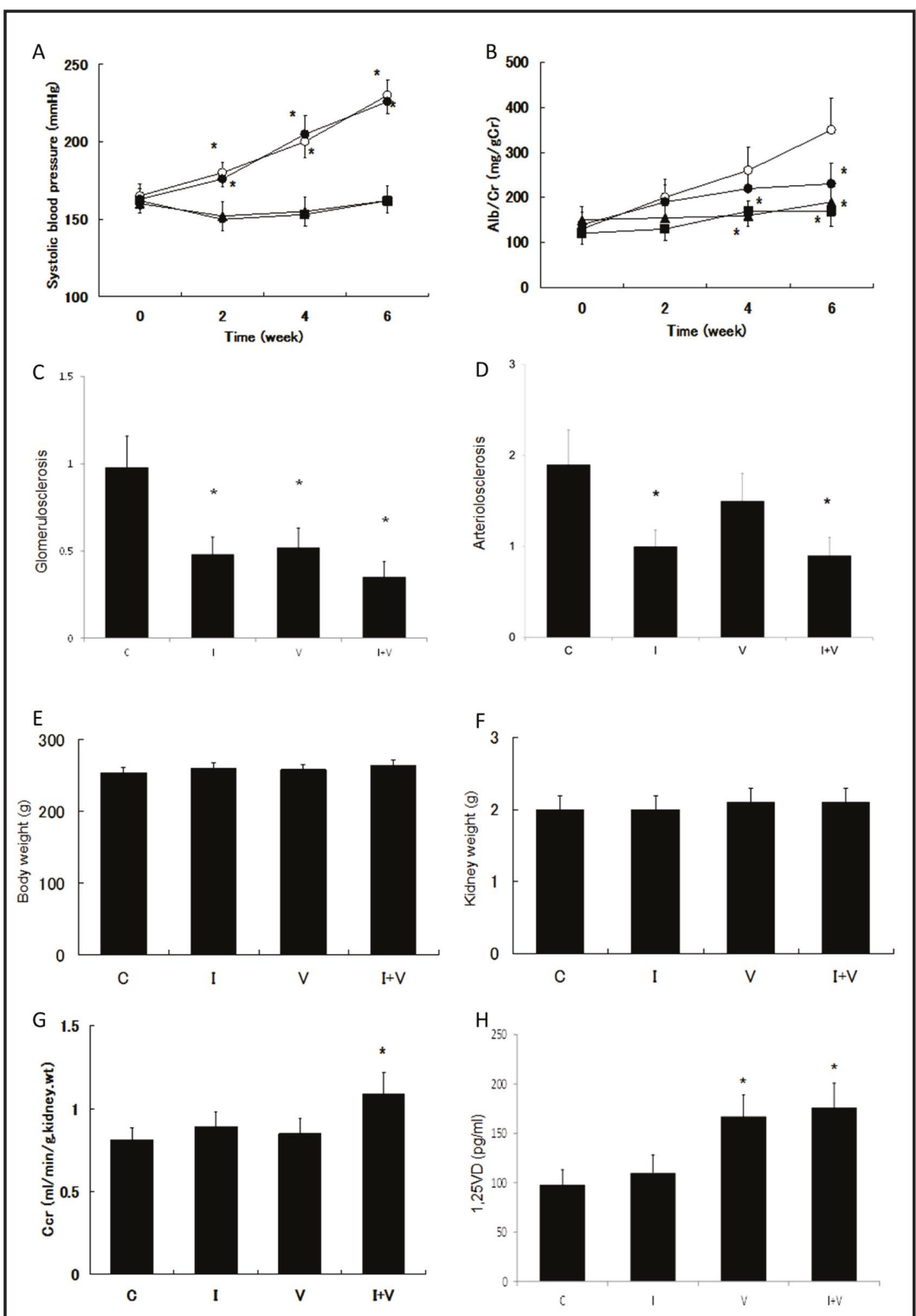

$p<0.05)$ compared with that in the $C$ group $(0.8 \pm 0.1 \mathrm{~mL} / \mathrm{min} / \mathrm{g}$ kidney weight $)$. Figure $1 \mathrm{H}$ indicates that serum active vitamin D levels were higher in groups $V(167 \pm 22 \mathrm{pg} / \mathrm{mL})$ and $\mathrm{I}+\mathrm{V}(176 \pm 24 \mathrm{pg} / \mathrm{mL})$ than in group C $(98 \pm 15 \mathrm{pg} / \mathrm{mL}, p<0.05)$, suggesting that the calcitriol infusion at the dose used rendered its serum concentration closer to the normal range.

Hormonal data: Plasma AngII levels in the C group ( $88 \pm 13 \mathrm{pg} / \mathrm{mL})$ were higher than those in the $\mathrm{V}$ group $(35 \pm 6 \mathrm{pg} / \mathrm{mL}, p<0.01)$ and lower than those in the I group $(138 \pm 17 \mathrm{pg} / \mathrm{ml}, p<0.05)$ (Figure 2A). In contrast (Figure 2B), kidney AngII levels were higher in the $\mathrm{C}$ group $(150 \pm 19 \mathrm{fmol} / \mathrm{g})$ than in the I $(104 \pm 15 \mathrm{fmol} / \mathrm{g}, p<0.05)$ and $\mathrm{I}+\mathrm{V}$ groups (102 $\pm 12 \mathrm{fmol} / \mathrm{g}, p<0.05)$. As summarized in Figure 2C, serum klotho levels were preserved in the $\mathrm{V}(209 \pm 29 \mathrm{pg} / \mathrm{mL}, p<0.01)$ and $\mathrm{I}+\mathrm{V}$ groups $(200 \pm 21 \mathrm{pg} / \mathrm{mL}, p<0.05)$ compared with those in the C group $(119 \pm 15 \mathrm{pg} / \mathrm{mL})$. Similarly, Figure 2D illustrates that the kidney klotho expression in the $\mathrm{C}$ group $(21 \pm 6 \%)$ was lower than that in groups $\mathrm{V}$ $(50 \pm 14 \%, p<0.05)$ and $\mathrm{I}+\mathrm{V}(59 \pm 17 \%, p<0.01)$. Plasma renin activity in the $\mathrm{C}$ group was higher than that in the V group $(p<0.05)$, but lower than that in the I group $(p<0.05)$ (Figure 2E). The chimera protein composed of the extracellular domain of klotho and IgG was 


\section{Kidney Blood Pressure Research}

Fig. 2. Systemic and renal levels of angiotensin II and klotho. Plasma angiotensin II was elevated in I group, and suppressed in V groups (A). Kidney angiotensin II was diminished in I and $\mathrm{I}+\mathrm{V}$ groups (B). Serum klotho was elevated in $\mathrm{V}$ and $\mathrm{I}+\mathrm{V}$ groups (C). Kidney klotho expression was preserved in $\mathrm{V}$ and $\mathrm{I}+\mathrm{V}$ groups (D). Plasma renin activity (PRA, E) showed similar trends with plasma angiotensin II. * indicates $\mathrm{p}<0.05$ vs. C ( 6 animals for each group).

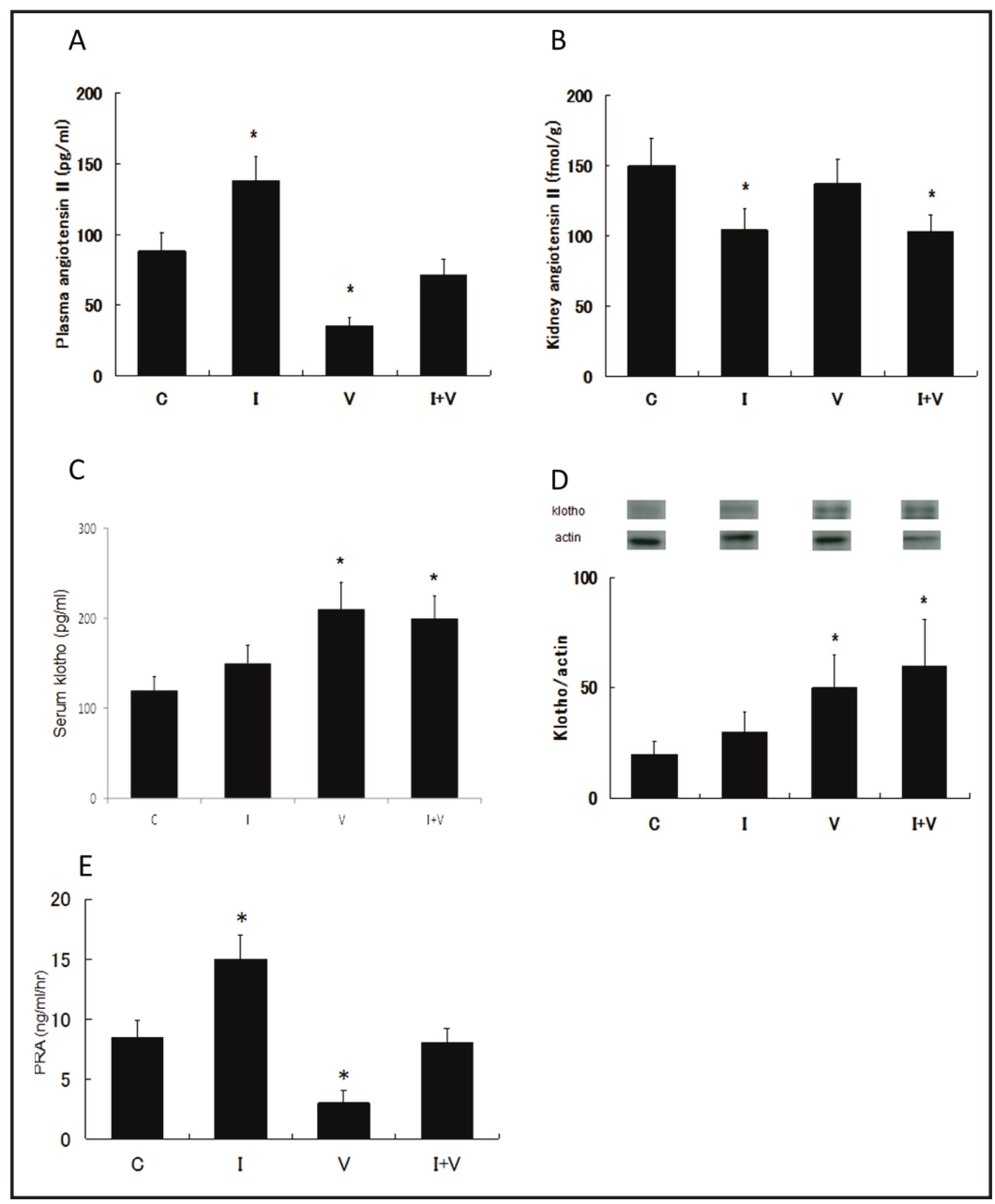

observed to bind to endothelial cells (Figure 3). In contrast, the extracellular domain of klotho failed to show significant binding to tubular epithelium in vitro.

Arterial function: As depicted in Figure $4 \mathrm{~A}$, the increase in urinary excretion of 8 epiprostaglandin $\mathrm{F} 2 \alpha$ was suppressed in groups $\mathrm{V}(8.5 \pm 1.0 \mathrm{ng} /$ day $)$ and $\mathrm{I}+\mathrm{V}(7.1 \pm 0.8 \mathrm{ng} /$ day) but not in the $C$ group $(15.8 \pm 2.0 \mathrm{ng} /$ day, $p<0.05$ for each) at 6 weeks. Figure 4B summarizes the augmented depressor responses to $1 \mu \mathrm{g}$ of acetylcholine in groups $\mathrm{V}(-38 \pm 4 \%)$ and $\mathrm{I}+\mathrm{V}(-35 \pm 3 \%)$ compared with those in group C $(-15 \pm 2 \%, p<0.05$ for each). However, acetylcholine failed to elicit considerably greater responses in the I group $(-21 \pm 2 \%)$. Expression of eNOS tended to be higher in the I and I+V groups, although statistical significance was not attained (Figure 4C). However, as shown in Figure 4D, SOD expression was enhanced in groups $\mathrm{V}$ $(3.5 \pm 0.9)$ and $\mathrm{I}+\mathrm{V}(3.4 \pm 0.8)$ compared with

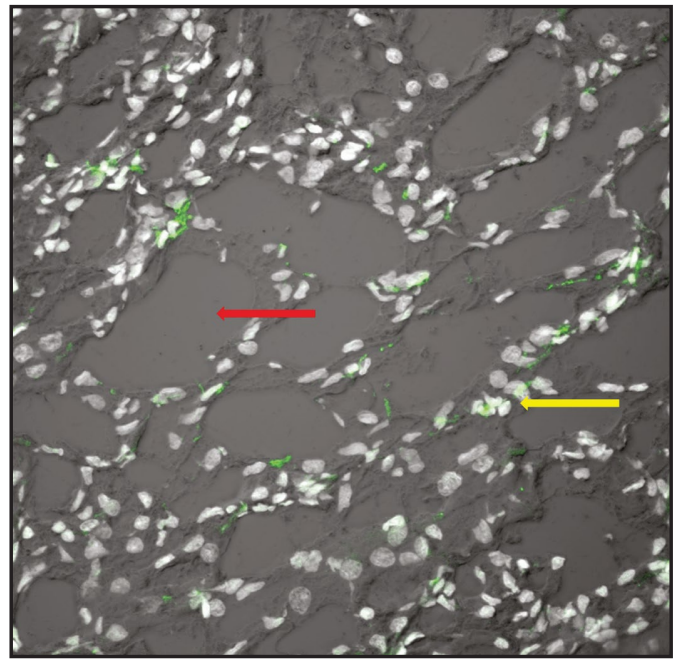

Fig. 3. Extracellular domain of klotho binds to kidney tissue, especially with endothelium ( $\mathrm{x} 400)$. Although tubular epithelium (red arrow) failed to show significant binding, endothelial cells (yellow arrow) exhibit considerable bindings to extracellular domain of klotho as colored in green. 


\section{Kidney \\ Blood Pressure \\ Research}

Fig. 4. Temporal changes in 8-epi-prostaglandin F2a excretion (A). ocontrol (C), $\Delta$ irbesar$\tan (\mathrm{I})$, •viamin D (V), -irbesartan with vitamin $\mathrm{D}(\mathrm{I}+\mathrm{V})$, * indicates significant difference from C (6 animals for each group). Depressor responses to acetylcholine (B). Open bar: C, oblique bar: I, hatched bar: V, closed bar: I+V. * depicts $\mathrm{p}<0.05$ vs. C (6 animals for each group). Expression of endothelial nitric oxide synthase (eNOS, C) and superoxide dismutase (SOD) (6 animals for each group). SOD was elevated in $\mathrm{V}$ and $\mathrm{I}+\mathrm{V}$ groups (D). Serum calcium (E) and phosphate levels (F) were similar among 4 groups (6 animals for each group).
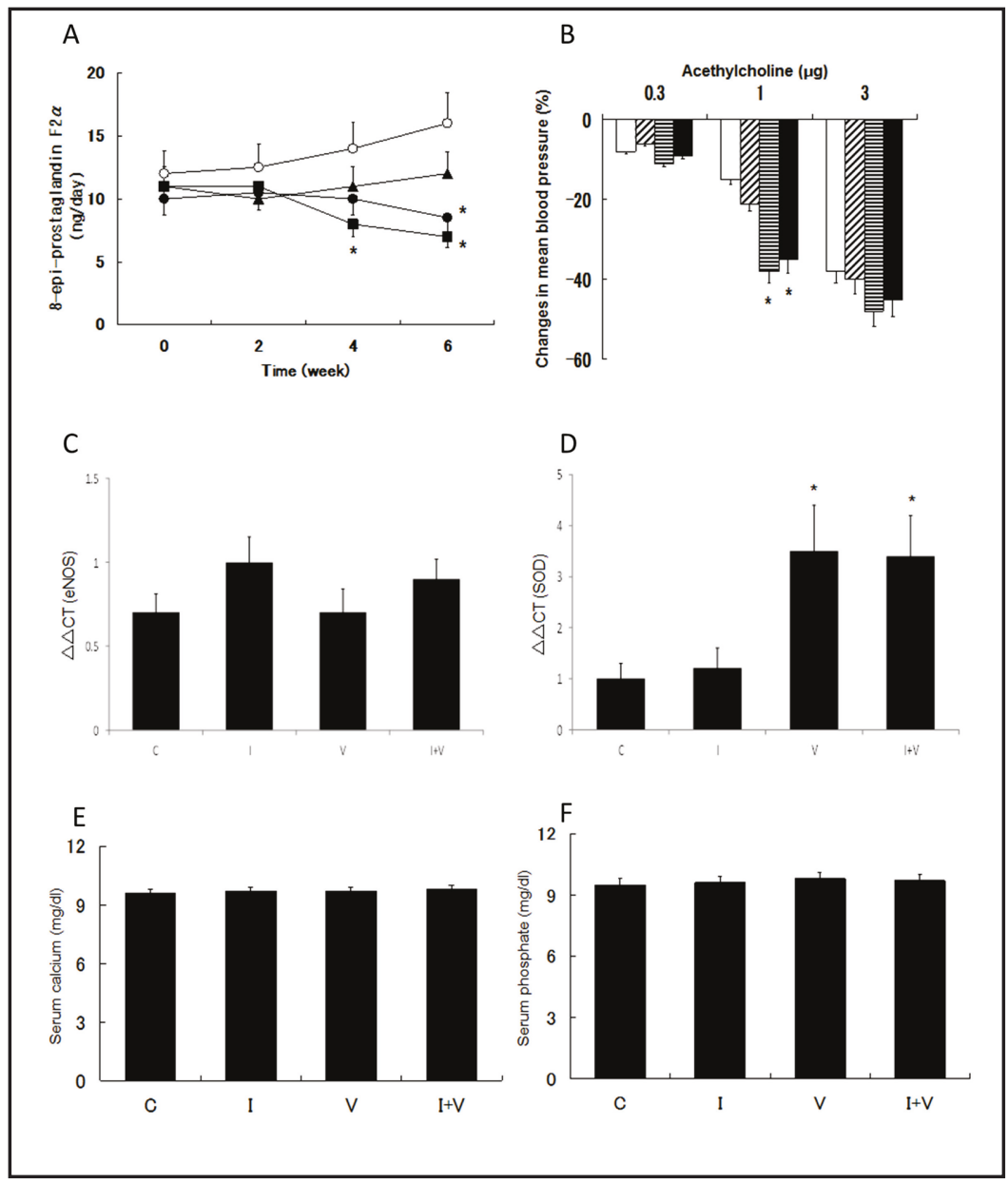

that in group C $(1.0 \pm 0.3, p<0.05$ for each). Serum calcium and phosphate levels did not differ among the 4 groups at 6 weeks (Figures $4 \mathrm{E}$ and $4 \mathrm{~F}$ ).

\section{Discussion}

The RAS plays an important role in the pathogenesis of hypertension [1, 2]. In normotensive animals, plasma AngII level is averaged to be $21 \mathrm{pg} / \mathrm{mL}$ [20]. In comparison, plasma AngII levels in the $C$ group were elevated. In addition, the present data show that SBP considerably decreased in both I and I+V groups, demonstrating that the RAS contributes to the maintenance of high blood pressure in this model. Irbesartan markedly reduced UAE and ameliorated arteriolosclerosis. This supports the notion that ARBs exert renoprotective actions in hypertensive renal injury [1]. However, SBP was similar between groups C and V. Although the dose of vitamin D was chosen not to worsen hyperphosphatemia to prevent phosphate toxicity [16], it may not be sufficient to decrease blood pressure [23, 24].

Recent analyses reported that vitamin D treatment reduced proteinuria in CKD [24, 25]. In consistent, the present findings indicate that UAE was moderately albeit significantly decreased in the $\mathrm{V}$ group. Histological examinations revealed that glomerular sclerosis improved in group $\mathrm{V}$ as well as in groups I and $\mathrm{I}+\mathrm{V}$. Our data that 8-epi-prostaglandin F2 $\alpha$ excretion was reduced in the $V$ group at 6 weeks suggest that vitamin D ameliorates oxidative stress in hypertensive renal injury, leading to suppression of glomerular sclerosis. The present results showed that creatinine clearance was preserved in the $I+V$ group. These findings indicate that in addition to high blood pressure, the activation of RAS and oxidative 


\section{Kidney Blood Pressure Research}

\begin{tabular}{l} 
Kidney Blood Press Res 2014;39:17-27 \\
\hline \begin{tabular}{l|l} 
DOI: 10.1159/000355773 & $\begin{array}{l}\text { O 2014 S. Karger AG, Basel } \\
\text { www.karger.com/kbr }\end{array}$ \\
Published onlIne: April 30, 2014 &
\end{tabular}
\end{tabular}

Takenaka/Inoue/Ohno/Miyazaki/Nishiyama/Ishii/Suzuki: Klotho and Endothelium

stress are involved in the progression of hypertensive renal dysfunction. Administration of soluble klotho protein into klotho gene knockout mice increased creatinine clearance [12]. Taken together, these suggest that both klotho induction and RAS inhibition are required to effectively preserve renal function.

Saito et al. indicated that klotho-deficient animals showed marked endothelial dysfunction, which was reversed by parabiosis with a wild-type animal, suggesting the involvement of a hormonal factor [26]. Consistent with this, our data clearly shows that the extracellular domain of klotho protein binds to endothelial cells. Klotho interacts with various proteins, including transient receptor potential channel (TRPC), WNT, receptors for vascular endothelial growth factor, FGF23, and transforming growth factor- $\beta$ [9, 27-31]. Kurosu et al. suggests that free klotho interacts with IGF receptors to modulate their signaling and induce SOD expression [31]. Klotho maintains endothelial integrity by modifying calcium influx through TRPC1 [27]. Soluble klotho inhibits TRPC6 currents in cardiomyocytes [28]. Previous studies demonstrated that calcium influx through TRPCs mediates glomerular arteriolar constriction by AngII $[32,33]$. Free klotho can interact with TRPCs on all cells, including vascular myocytes, thereby reducing efferent arteriolar resistance that lowers the glomerular pressure and albuminuria. Furthermore, excessive calcium entry through TRPC6 on podocytes could cause injury [34]. Thus, the anti-proteinuric action of vitamin D may involve free klotho, which possibly reduces calcium entry through TRPCs into efferent arteriolar myocytes and podocytes.

The present data indicate that depressor responses to acetylcholine were exaggerated in the $\mathrm{V}$ and $\mathrm{I}+\mathrm{V}$ groups compared with those in the $\mathrm{C}$ group. This suggests that vitamin D supplementation reverses endothelium-dependent vasodilation in this model. As serum calcium and phosphate levels were similar among the 4 groups, it is unlikely that the consequences of abnormal calcium or phosphate metabolism could confound the data interpretation [16]. Nakamura et al. reported that eNOS expression was reduced in klothodeficient animals [35]. Klotho binds to endothelial cells and vitamin D increases serum klotho levels. Thus, eNOS expression was examined. However, the present data indicates that eNOS expression was not elevated in the V group in which klotho expression was induced. Endothelial damage caused by hypertension may have prevented significant improvement of aortic eNOS in the $V$ group. In addition, ARBs enhance eNOS expression through the activation of AT2 receptors [36]. Although eNOS expression was prone to be elevated in the I and I+V groups, statistical significance was not obtained. The data that 8-epi-prostaglandin F2 $\alpha$ excretion was suppressed in the $\mathrm{V}$ and $\mathrm{I}+\mathrm{V}$ groups suggest that vitamin $\mathrm{D}$ reduces oxidative stress. Indeed, aortic SOD expression was elevated in the $\mathrm{V}$ and $\mathrm{I}+\mathrm{V}$ groups. Consistent with the findings of a previous study [31], our data suggest that klotho induces SOD expression, eliminating reactive oxygen species with an enhancement of endothelium-dependent responses.

Consistent with the results of a previous study [37], the present data indicate that irbesartan elevates plasma AngII levels and lowers kidney AngII levels. ARBs increase renin release, which would account for an increment of the plasma AngII levels in the I group. As seen in various CKD models, AngII stimulates renal angiotensinogen production [37]. Thus, ARBs lower renal angiotensinogen with a resultant decrease, rather than an increase, in renal AngII levels, leading to low renal AngII levels in the I group. Our results differ from previous studies, which showed that losartan increased renal AngII and vitamin D decreased it $[4,5]$. Although the exact reasons for these diverse results are unclear, they may be attributed to differing ARBs, methods of measuring AngII levels, and the renal disease models used. In addition, vitamin D decreases renin expression [3]. Accordingly, plasma renin activity and AngII levels reduced in the V group. However, the present data that renal AngII levels in the $\mathrm{V}$ group were similar to those of the $\mathrm{C}$ group indicate that renin inhibition by supplemental vitamin D was inadequate to suppress the renal AngII levels, and support the notion that renal RAS is independent of systemic RAS [37]. In the present study, both renal and serum klotho levels were elevated in the $\mathrm{V}$ and $\mathrm{I}+\mathrm{V}$ groups compared with those in the $\mathrm{C}$ group. In contrast to RAS, circulating klotho depends at least in part on renal klotho. 


\section{Kidney \\ Blood Pressure Research}

Our study has limitations. First, klotho-deficient animals were not used, as we wanted to examine the effects of vitamin D on klotho expression. Experiments using exogenous klotho protein are ongoing as separate studies. Second, RAS inhibition is reported to upregulate renal klotho expression, which is diminished in various CKDs $[1,38]$. However, the present results failed to support the above findings. Compared to the $\mathrm{C}$ group, renal klotho expression and serum klotho level tended to be elevated in the I group, but they did not attain statistical significance. Independent of AngII, oxidative stress by itself also diminishes klotho expression [39]. Salt as well as AngII induce oxidative stress [40]. Furthermore, klotho gene transfer ameliorates AngII-induced renal damage [10]. Our observations suggest that vitamin D-enhanced klotho expression helps retard hypertensive renal damage, in which AngII is involved.

\section{Conclusions}

RAS inhibition aids in protecting the kidneys by improving blood pressure and renal AngII levels. Renal protection by calcitriol appears to be mediated by lowering the levels of circulating AngII and oxidative stress and by increasing klotho expression. Klotho secretion shows additional beneficial effects on remote endothelial functions, as exemplified by improved endothelium dependent vasodilation. Thus, combined treatment with RAS inhibition and vitamin D supplementation appears effective in delaying the progression of renal dysfunction in hypertensive patients with CKDs, in whom the activation of vitamin $D$ is suppressed. Furthermore, vitamin D supplementation for the patients with nephrosclerosis should not only suppress RAS but also increase renal and free klotho levels, thereby improving endothelial function and reducing oxidative stress and eventually preventing atherosclerotic cardiovascular complications.

\section{Disclosure Statement}

Conflicts of interest: Irbesartan was gifted from Dai-nippon Sumitomo Pharmaceuticals.

\section{Acknowledgments}

This study was supported in part by grants from the Ministry of Education and Culture (25461229), Saitama Medical University (20-1-2-07) and Dai-nippon Sumitomo Pharmaceuticals. Parts of the data in this manuscript were presented at the Council for High Blood Pressure Research Scientific Sessions, September 2013, in New Orleans, LA, USA, and published as an abstract. The authors thank Ms. Aya Matsuda of Kagawa University and Mami Fukuoka and Makiko Sato of Saitama Medical University for their excellent technical help.

\section{References}

1 de Borst MH, Vervloet MG, ter Wee PM, Navis G: Cross talk between the renin-angiotensinaldosterone system and vitamin D-FGF-23-klotho in chronic kidney disease. J Am Soc Nephrol 2011;22:1603-1609.

- 2 Takenaka T, Suzuki H, Furukawa T, Ogata Y, Saruta T: Role of intrarenal renin-angiotensin system on pressure-natriuresis in spontaneously hypertensive rats. Clin Exp Hypertens 1990;12:1377-1394.

-3 Li YC, Kong J, Wei M, Chen ZF, Liu SQ, Cao LP: 1,25-Dihydroxyvitamin D(3) is a negative endocrine regulator of the renin-angiotensin system. J Clin Invest 2002;110:229-238. 


\section{Kidney \\ Blood Pressure Research}

Kidney Blood Press Res 2014;39:17-27

\begin{tabular}{l|l}
\hline DOI: $10.1159 / 000355773$ & C 2014 S. Karger AG, Basel \\
Publisned ontIne: AprII 30, 2014 & www.karger.com/kbr
\end{tabular}

-4 Deb DK, Sun T, Wong KE, Zhang Z, Ning G, Zhang Y, Kong J, Shi H, Chang A, Li YC: Combined vitamin $\mathrm{D}$ analog and AT1 receptor antagonist synergistically block the development of kidney disease in a model of type 2 diabetes. Kidney Int 2010;77:1000-1009.

-5 Zhang Z, Zhang Y, Ning G, Deb DK, Kong J, Li YC: Combination therapy with AT1 blocker and vitamin D analog markedly ameliorates diabetic nephropathy. Proc Natl Acad Sci USA 2008;105:15896-15901.

-6 Fried LF, Emanuele N, Zhang JH, Brophy M, Conner TA, Duckworth W, Leehey DJ, McCullough PA, O'Connor T, Palevsky PM, Reilly RF, Seliger SL, Warren SR, Watnick S, Peduzzi P, Guarino P; VA NEPHRON-D Investigators: Combined Angiotensin inhibition for the treatment of diabetic nephropathy. N Engl J Med 2013;369:1892-1903.

-7 Wolden-Kirk H, Gysemans C, Verstuyf A, Mathieu C: Extraskeletal effects of vitamin D. Endocrinol Metab Clin North Am 2012;41:571-594.

-8 Kurosu H, Ogawa Y, Miyoshi M, Yamamoto M, Nandi A, Rosenblatt KP, Baum MG, Schiavi S, Hu M-C, Moe OW, Kuro-o M: Regulation of Fibroblast Growth Factor-23 Signaling by Klotho. J Biol Chem 2006;281:6120-6123.

-9 Urakawa I, Yamazaki Y, Shimada T, Iijima K, Hasegawa H, Okawa K, Fujita T, Fukumoto S, Yamashita T: Klotho converts canonical FGF receptor into a specific receptor for FGF23. Nature 2006;444:770-774.

-10 Mitani H, Ishizaka N, Aizawa T, Ohno M, Usui S, Suzuki T, Amaki T, Mori I, Nakamura Y, Sato M, Nangaku M, Hirata Y, Nagai R: In vivo klotho gene transfer ameliorates angiotensin II-induced renal damage. Hypertension 2002;39:838-843.

- 11 Haruna Y, Kashihara N, Satoh M, Tomita N, Namikoshi T, Sasaki T, Fujimori T, Xie P, Kanwar YS: Amelioration of progressive renal injury by genetic manipulation of Klotho gene. Proc Natl Acad Sci USA 2007;104:2331-2336.

12 Chen TH, Kuro-O M, Chen CH, Sue YM, Chen YC, Wu HH, Cheng CY: The secreted Klotho protein restores phosphate retention and suppresses accelerated aging in Klotho mutant mice. Eur J Pharmacol 2013;698:67-73.

-13 Takenaka T, Watanabe Y, Inoue T, Miyazaki T, Suzuki H: Fibroblast growth factor 23 enhances renal klotho abundance. Pflugers Arch 2013;465:935-943.

-14 Mashimo T, Nabika T, Kitada K, Serikawa T, Matsumoto C, Ikeda K, Nara Y, Masuda J, Yamori Y, Ohno Y, Saruta T: Mapping of four simple sequence repeat (SSR) markers on rat chromosome 4. Hypertens Res 2000;23:47-50.

-15 Fukui T, Munemura C, Maeta S, Ishida C, Murawaki Y: The effects of olmesartan and alfacalcidol on renoprotection and klotho gene expression in 5/6 nephrectomized spontaneously hypertensive rats. Yonago Acta Med 2011;54:49-58.

-16 Razzaque MS: Phosphate toxicity: new insights into an old problem. Clin Sci (Lond) 2011;120:91-97.

17 Kanno Y, Okada H, Takenaka T, Saruta T, Suzuki H: Influence of the timing of initiating antihypertensive therapy in hypertensive rats with renal failure. Clin Exp Hypertens 2000;22:521529.

-18 Takenaka T, Suzuki H, Sakamaki Y, Itaya Y, Saruta T: Contribution of prostaglandins to pressure natriuresis in Dahl salt-sensitive rats. Am J Hypertens 1991;4:489-493.

19 Nishiyama A, Seth DM, Navar LG: Renal interstitial fluid concentrations of angiotensins I and II in anesthetized rats. Hypertension 2002;39:129-134.

-20 Takenaka T, Inoue T, Ohno Y, Miyazaki T, Nishiyama A, Ishii N, Suzuki H: Elucidating mechanisms underlying altered renal autoregulation in diabetes. Am J Physiol Regul Integr Comp Physiol 2012;303:R495-R504.

21 Miyazaki T, Takenaka T, Inoue T, Sato M, Eiki Y, Nodera M, Hanyu M, Ohno Y, Shibasaki S, Suzuki H: Zinc deficiency may accelerate aging by inhibiting klotho mRNA expression. Trace Nutr Res 2009;26:74-78.

-22 Takenaka T, Inoue T, Kanno Y, Okada H, Meaney KR, Hill CE, Suzuki H: Expression and role of connexins in the rat renal vasculature. Kidney Int 2008;73:415-422.

- 23 Kassi E, Adamopoulos C, Basdra EK, Papavassiliou AG: Role of vitamin D in atherosclerosis. Circulation 2013;128:2517-2531.

-24 de Zeeuw D, Agarwal R, Amdahl M, Audhya P, Coyne D, Garimella T, Parving HH, Pritchett Y, Remuzzi G, Ritz E, Andress D: Selective vitamin D receptor activation with paricalcitol for reduction of albuminuria in patients with type 2 diabetes (VITAL study). Lancet 2010;376:1543-1551. 


\section{Kidney \\ Blood Pressure Research}

\begin{tabular}{|c|c|}
\hline Kidney Blood Press Res 2 & \\
\hline $\begin{array}{l}\text { DOI: 10.1159/000355773 } \\
\text { Publisned onine: April 30, } 2014\end{array}$ & $\begin{array}{l}\text { (c) } 2014 \text { S. Karger AG, Basel } \\
\text { www.karger.com/kbr }\end{array}$ \\
\hline
\end{tabular}

25 de Borst MH, Hajhosseiny R, Tamez H, Wenger J, Thadhani R, Goldsmith DJ: Active vitamin $\mathrm{D}$ treatment for reduction of residual proteinuria: a systematic review. J Am Soc Nephrol 2013;24:1863-1871.

-26 Saito Y, Yamagishi T, Nakamura T, Ohyama Y, Aizawa H, Suga T, Matsumura Y, Masuda H, Kurabayashi M, Kuro-o M, Nabeshima Y, Nagai R: Klotho protein protects against endothelial dysfunction. Biochem Biophys Res Commun 1998;248:324-329.

-27 Kusaba T, Okigaki M, Matui A, Murakami M, Ishikawa K, Kimura T, Sonomura K, Adachi Y, Shibuya M, Shirayama T, Tanda S, Hatta T, Sasaki S, Mori Y, Matsubara H: Klotho is associated with VEGF receptor-2 and the transient receptor potential canonical-1 Ca2+ channel to maintain endothelial integrity. Proc Natl Acad Sci USA 2010;107:19308-19313.

-28 Xie J, Cha S-K, An S-W, Kuro-o M, Birnbaumer L, Huang C-L: Cardioprotection by Klotho through downregulation of TRPC6 channels in the mouse heart. Nat Commun 2012;3:1238.

29 Doi S, Zou Y, Togao O, Pastor JV, John GB, Wang L, Shiizaki K, Gotschall R, Schiavi S, Yorioka N, Takahashi M, Boothman DA, Kuro-o M: Klotho inhibits transforming growth factor-beta1 (TGF-beta1) signaling and suppresses renal fibrosis and cancer metastasis in mice. J Biol Chem 2011;286:86558665.

- 30 Liu H, Fergusson MM, Castilho RM, Liu J, Cao L, Chen J, Malide D, Rovira II, Schimel D, Kuo CJ, Gutkind JS, Hwang PM, Finkel T: Augmented Wnt signaling in a mammalian model of accelerated aging. Science 2007;317:803-806.

-31 Kurosu H, Yamamoto M, Clark JD, Pastor JV, Nandi A, Gurnani P, McGuinness OP, Chikuda H, Yamaguchi M, Kawaguchi H, Shimomura I, Takayama Y, Herz J, Kahn CR, Rosenblatt KP, Kuro-o M: Suppression of aging in mice by the hormone Klotho. Science 2005;309:1829-1833.

-32 Takenaka T, Suzuki H, Okada H, Inoue T, Kanno Y, Ozawa Y, Hayashi K, Saruta T: Transient receptor potential channels in rat renal microcirculation: actions of angiotensin II. Kidney Int 2002;62:558565.

- 33 Fellner SK, Arendshorst WJ: Angiotensin II-stimulated Ca2+ entry mechanisms in afferent arterioles: role of transient receptor potential canonical channels and reverse $\mathrm{Na}+\mathrm{Ca} 2+$ exchange. Am J Physiol 2008;294:F212-F219.

-34 Mukerji N, Damodaran TV, Winn MP: TRPC6 and FSGS: the latest TRP channelopathy. Biochim Biophys Acta 2007;1772:859-868.

-35 Nakamura T, Saito Y, Ohyama Y, Masuda H, Sumino H, Kuro-o M, Nabeshima Y, Nagai R, Kurabayashi M: Production of nitric oxide, but not prostacyclin, is reduced in klotho mice. Jpn J Pharmacol 2002;89:149-156.

- 36 Thai H, Wollmuth J, Goldman S, Gaballa M: Angiotensin subtype 1 Receptor (AT1) blockade improves vasorelaxation in heart failure by up-regulation of endothelial nitric-oxide synthase via activation of the AT2 receptor. J Pharmacol Exp Ther 2003;307:1171-1178.

-37 Kobori H, Nangaku M, Navar LG, Nishiyama A: The intrarenal renin-angiotensin system: from physiology to the pathobiology of hypertension and kidney disease. Pharmacol Rev 2007;59:251287.

- 38 Yoon HE, Ghee JY, Piao S, Song JH, Han DH, Kim S, Ohashi N, Kobori H, Kuro-o M, Yang CW: Angiotensin II blockade upregulates the expression of Klotho, the anti-ageing gene, in an experimental model of chronic cyclosporine nephropathy. Nephrol Dial Transplant 2011;26:800-813.

-39 Mitobe M, Yoshida T, Sugiura H, Shirota S, Tsuchiya K, Nihei H: Oxidative stress decreases klotho expression in a mouse kidney cell line. Nephron Exp Nephrol 2005;101:e67-e74.

-40 Abe M, O'Connor P, Kaldunski M, Liang M, Roman RJ, Cowley AW Jr.: Effect of sodium delivery on superoxide and nitric oxide in the medullary thick ascending limb. Am J Physiol 2006;291:F350-F357. 